\title{
Serial Innovators in the UK: Does Size matter?
}

\begin{abstract}
This paper aims to shed light on the presence and importance of a significant number of small firms amongst serial innovators. Contrary to the common expectation in the innovative persistence literature, we posit that also small serial innovators benefit from operating within patterns of creative accumulation. However, it is in the quality of the technology and in the very nature of the knowledge accumulation process that the differences between small and large serial innovators can be found. Using a sample of 811 UK-based, highly innovative companies that patented over 66000 inventions from 1990 to 2006, we find evidence in support of our theory. While large serial innovators experience higher innovation rates due to the scale of their innovation efforts to generate further innovations, small serial innovators benefit more from processes of search depth characterised by the internal recombination of previous own knowledge. We find that fundamental differences exist also in the very nature of the technologies being developed.
\end{abstract}




\section{Introduction}

The literature on technological change assumes persistence in innovation to take place within a technological environment characterized by Schumpeterian patterns of creative accumulation, where innovation advantages due to knowledge accumulation and technological learning generate concentration-increasing growth (Schumpeter, 1942; Nelson and Winter, 1982). Such patterns are characterised by high barriers to innovative entry, stability in the ranks of innovators and routinised processes that sustain the innovative activity of a small number of large established firms competing in highly concentrated oligopolies (Winter, 1984; Malerba and Orsenigo, 1996, 1999).

In this picture, small firms have a smaller presence and a lower likelihood of survival (Acs and Audretsch, 1987; Audretsch, 1995). Thus, while the relationship between firm size and innovation persistence is acknowledged to be non-linear, with many large firms showing no sign of persistence and some small firms being persistent innovators (Cefis and Orsenigo, 2001; Geroski et al., 1997; Malerba et al., 1997), the emphasis in the literature has traditionally been on large firms. Conversely, the specific characteristics of persistently innovating small firms and the differences with their large counterparts have been much overlooked. This paper contributes to the innovative persistence literature by exploring this question in more detail.

We argue that innovation persistence is defined by the role of technological regimes characterised by high opportunity conditions and cumulativeness discussed by previous literature, as well as the specific technological characteristics of the innovations, such as technological impact, generality and originality.

While we expect these effects to apply to all serial innovators, we suggest important differences can be found in the very nature of the process of knowledge accumulation defined 
by the fundamental differences in the scale and structure of small and large firms. While the presence of dynamic economies of scale in innovation is important for both the small and large serial innovators, the larger scale of research activity makes this effect more prominent among large firms. Similarly, while both small and large serial innovators build on their existing accumulated knowledge trajectory to generate future inventions, we posit the specialised technological nature of small serial innovators leads to more pronounced dynamic increasing returns resulting from search depth defined by the exploitation of the internal combinative capabilities and knowledge spillovers from previous innovative activities.

We posit that differences between large and small serial innovators are to be found also in the technology specific characteristics. In particular, we expect small serial innovators to benefit more than large serial innovators from high impact technologies, as they signal and reinforce their presence and dominance in a specialised technological niche and further increase the potential for internal knowledge spillovers.

Using patent data from the EPO PATSTAT database for the period between 1990 and 2006, we identify those UK companies characterized by a sustained record of inventive activity over time, defined as serial innovators ${ }^{1}$, and explore the effects that specific patterns of innovative activity and firm-specific technology characteristics exert on their rate of innovation. In particular, we offer a comparative perspective between small and large serial innovators in order to shed light on the moderating effects of firm size through which innovative persistence manifests itself.

We find that small serial innovators, like their large counterparts, benefit from an environment replete with innovative opportunities and also from their accumulated competencies to sustain their innovative activities. In line with our research hypotheses, we find that it is in the role played by the scale of knowledge accumulation and the degree to 
which firms build on their existing knowledge for further inventions that the main difference between small and large serial innovators can be found.

Our results also provide partial evidence that patents characterised by high impact, generality and originality allow all serial innovators to sustain persistence innovation. At the same time, we find that small serial innovators benefit more than large serial innovators from highquality patents that reflect knowledge specialization in defined technological fields.

These findings address an important gap in the innovative persistence literature by shedding more light on small serial innovators and by highlighting that subtle, yet important differences remain in how innovative persistence occurs in small and large serial innovators.

The rest of the paper is organised as follows. Section 2 presents a review of the background literature and the hypotheses, Sections 3 and 4 outline the data and the methodology, Section 5 discusses the results and Section 6 concludes the paper.

\section{Literature Review and Hypotheses}

The literature suggests that a number of factors characterize persistent innovation. In Section 2.1, we concentrate on the characteristics of technological regimes while in Section 2.2 we consider technology-specific characteristics as important determinants of persistent innovative activity. Each section includes the relevant hypotheses to be tested in the empirical part of the paper.

\subsection{The characteristics of technological regimes}

Several empirical studies demonstrate that persistence in innovative activity may be explained through qualities of the relevant technological regime (Malerba and Orsenigo, 
1996; Breschi et al., 2000), which can be seen as the knowledge environment shaping the firm-specific routines and boundaries; thus defining firms' technological trajectory (Nelson and Winter, 1982; Dosi, 1982). Four main dimensions have been used to describe technological regimes, namely opportunity conditions, appropriability conditions, properties of the knowledge base and cumulativeness of innovation.

(a) Opportunity conditions describe the increase in sectoral innovative activities for a given amount of resources spent in search (Malerba and Orsenigo, 1993). By generating a rich innovative environment, opportunity conditions widen the scope of firms' technological frontier. At the same time, they may ease the effect of size-related disadvantages allowing for small innovators to exist alongside large ones (Audretsch, 1995).

(b) Appropriability conditions express the possibility for the firm to protect its inventions. High levels of appropriability are associated with a more persistent pattern of innovative activity since securing the returns to innovation provides resources and incentives for further innovation. Companies use a wide range of formal and informal protection methods for their innovations. Moreover, their use in different industries can vary significantly (Levin et al., 1987; Arundel and Kabla, 1998). Patent data used in this paper present a limitation in this respect, and we need to make an assumption on the level of appropriability in our dataset. Given the high cost of patenting, we argue that companies which present a sustained level of patenting activity are likely to consider patents an efficient and viable method of protection, in line with the findings in Arundel (2001). Therefore, we assume a high level of appropriability for all companies in this study.

(c) Properties of the knowledge base refers to the multidimensional complexity of the technological knowledge on which the firm's innovative efforts are built. While the theory 
identifies various characteristics such as specificity, tacitness and complexity (Winter, 1987), previous research has usually measured this variable using the simpler dichotomy between applied and science-based technology (Breschi et al., 2000). In this context, science-based technology is associated with codified and easily transferrable knowledge, while applied technology is sector specific and requires accumulated capabilities to be fully exploited (Winter, 1984).

(d) Cumulativeness describes the degree to which innovations in a specific period of time depend on previous innovations. This aspect of the knowledge regime has been the most extensively discussed aspect in the innovative persistence literature (Malerba and Orsenigo, 1993) and two main elements of cumulativeness have been proposed to explain the presence of persistence in innovation. The first element is 'dynamic economies of scale', where the volume of previous innovation exerts a positive effect on the successive rounds of innovations, as commercial success and the firm's enriched absorptive capacity provide the resources that sustain new research activities (Nelson and Winter, 1982; Cohen and Levinthal, 1989). In other words, "the more innovations a firm produces, the more likely it is to continue to innovate" (Geroski et al., 1997: 33). This hypothesis can also be seen as related to the concept of sunk costs (Sutton, 1991), as the accumulated stock of knowledge generates high barriers to entry and exit in innovation, thus supporting persistent innovation.

The second element is related to the notion of 'search depth', which describes "how deeply a firm reuses its existing knowledge" (Katila and Ahuja, 2002, p.1183). This reflects the ‘increasing returns' property of knowledge accumulation, as building upon, reusing and recombining its specialised knowledge results in the firm gaining a deeper understanding of internal technological components and capabilities (Hall et al., 2001; 2005). Such process promotes persistent innovation supporting a more effective selection and exploitation of related opportunities for future innovations (Kogut and Zander, 1992; Fleming, 2001). 
The abovementioned four dimensions of technology regimes (a-d) are important elements that shape the innovative activities of firms. Within the analytical framework of Schumpeterian patterns of technological change, persistence is an inherent quality of creative accumulation characterised by high opportunity and strict appropriability conditions, more cumulativeness and a knowledge base more applied in nature (Winter, 1984; Malerba and Orsenigo, 1993; Breschi et al., 2000). Accordingly, we hypothesise that:

Hypothesis 1. For both small and large serial innovators, the rate of innovation is enhanced in the presence of high opportunity conditions, a knowledge base close to applied technology and high levels of cumulativeness.

While these characteristics are associated with innovative persistence dynamics for all serial innovators, we expect to find significant differences in the process of knowledge accumulation for small and large firms given their fundamental differences in terms of resources, markets and technological organization (Acs and Audretsch, 1987; Cohen and Klepper, 1996). As discussed above, knowledge accumulation benefits innovative persistence through two distinct, yet related channels: (1) scale effects and (2) search depth. While both channels are important for large and small serial innovators to develop further innovations and sustain persistence in innovation, significant differences exist in terms of how effectively these channels serve the two types of firms.

As dynamic economies of scale foster persistence through increased financial returns and enriched absorptive capacity, their presence may offer two advantages to large serial innovators as opposed to small ones. Operating on a larger scale across broader markets, 
large serial innovators can apply the fruits of their innovation over a greater output, attaining higher returns from an increasing volume of innovative activities (Nelson and Winter, 1982; Levin and Reiss, 1988; Cohen and Klepper, 1996). Similarly, large serial innovators are also engaged in a broader number of products and technological fields compared to small firms (Breschi et al., 2003; Corradini et al., 2012). In this sense, their broader search scope allows for a more effective application of the increasing stock of knowledge across the wider set of technological opportunities (Fleming, 2001; Katila and Ahuja, 2002). Therefore, we hypothesise that:

Hypothesis 2: Compared to small serial innovators, large serial innovators benefit more from scale effects in knowledge creation to enhance their rate of innovation.

The second dimension of cumulativeness, search depth (i.e. building on the firm's existing knowledge), is also an important facilitator of persistent innovation for both the small and large serial innovators. However, we expect the processes of search depth to be more important across small firms compared to large serial innovators.

Compared to large firms, the constraints in both resources and output of small firms limit their extent of scale effects in fostering further innovation and restrict their opportunities to explore knowledge sources outside the firm's knowledge base. In line with this, small serial innovators have been described as specialised technology developers centred on the development of a key core technology (Hicks and Hegde, 2005).

Previous literature on the economics of innovation indicates that focusing on previous internal knowledge to generate further innovation allows firms to develop a strong competitive position within a specific technological trajectory (Hall et al., 2005), as the enhanced combinative capabilities increase internal knowledge spillovers and improve the 
selection and the exploitation of useful components in future innovation (Fleming, 2001; Fleming and Sorenson, 2004). As focusing on core technological competencies allows small firms to avoid ineffective solutions in favour of more useful technological combinations (Freel, 2000; Nesta and Saviotti, 2005), processes of search depth may constitute a key element in fostering innovation persistence among small serial innovators.

Consequently, as small serial innovators narrow down in their technological trajectory and specialise within a niche of expertise, they can obtain greater benefits from search depth than large serial innovators which engage in a broader scale and scope of research activities. In fact, integrating and reconfiguring knowledge embedded in previous innovations becomes more complex when search activities grow in scale, and it can be increasingly difficult for large firms to manage and combine the greater number of different pieces of knowledge located in different parts of the organisation (Carlile, 2002). Thus, small serial innovators may benefit more from the increasing returns resulting from search depth into their existing core knowledge to generate further knowledge compared to large serial innovators. Therefore, we hypothesise:

Hypothesis 3. Compared to large serial innovators, small serial innovators benefit more from search depth to enhance their rate of innovation.

\subsection{Technology specific characteristics}

Technological regimes are essential in defining the technological trajectory followed by companies. Yet, their innovative behaviour is also shaped by the specific qualities of the technologies they develop. In particular, previous literature discusses elements of three main characteristics of technology - high impact, generality and originality - that it is possible to 
argue may exert an important role for serial innovators by generating technology dynamics that reinforce persistence in innovation.

The impact of innovation represents the value of a given technology. High impact technologies yield higher financial returns that can be channelled into further inventive efforts, and companies developing such innovations receive a higher market return for their innovations (Chen and Chang, 2010; Hall et al., 2005). At the same time, the higher impact of innovations reflects the higher quality of the knowledge creation process within firms' innovative activity (Trajtenberg, 1990) and reinforces their position over a specialised technological area. Thus, innovations with higher technological impact exert a strong effect on firms' accumulated technological competencies, providing new resources and knowledge for further inventive efforts.

Generality of innovation describes technology that is generic and can be used for the development of a wide variety of products. Generality of innovation resembles the concept of 'general purpose technology' (GPT) introduced by Bresnahan and Trajtenberg (1995). They describe GPTs as 'enabling technologies', characterized by high levels of dynamism and pervasiveness, which generate processes of 'innovational complementarity'. Innovations characterised by higher levels of generality act as platforms that enable the expansion and diversification of firms' technological trajectory in derivative technologies, opening up opportunities for further innovations and supporting innovative persistence (Kim and Kogut, 1996).

Originality of innovation indicates the degree to which a given innovation is novel or creative, encompassing a diverse set of previous ideas (Trajtenberg et al., 1997). Firms whose innovations derive from a broad range of technology fields demonstrate the presence 
of strong absorptive capacities and the ability to effectively synthesise different pieces of knowledge (Granstrand et al., 1997). Original innovations enrich firm's knowledge base and strengthen their position in a given technology. More generally, the may open up new opportunities to explore new technological possibilities across related and less related technology fields (Cohen and Levinthal, 1990), fostering technology persistence dynamics.

These three technology-specific qualities represent different channels that reinforce innovation persistence. High impact technologies sustain serial innovation by increasing the high quality knowledge available to the firm as well as providing financial returns that can fuel further innovative efforts. Similarly, original innovation has a widening effect on internal combinative capabilities and further technological search. Technologies that are general and have a wide applicability open up novel directions of research, fostering technology branching. Therefore, we hypothesise:

Hypothesis 4. High levels of technological impact, generality and originality in innovations enhance the rate of innovations for both small and large serial innovators.

As small serial innovators are more likely to focus on the opportunities arising from internal specialised knowledge, they are likely to gain more benefits from developing innovations that increase the number and the quality of potential knowledge combinations available to the firm. Such effects do not depend as much on the volume or breadth of innovation previously developed, but rather on the qualities of the knowledge created within the firm (Hicks and Hegde, 2005). 
High impact technologies provide companies with a richer and more valuable set of knowledge components, which increases the potential for internal knowledge spillovers along firms' specific research trajectory (Fleming, 2001). In this sense, as the quality of combinative opportunities generated by high impact technologies enhances the benefits that the process of search depth can offer, such technologies are likely to be particularly significant for small serial innovators specialised on a core technology where they possess advanced capabilities ${ }^{2}$. Moreover, they may reinforce the expertise and dominance of small serial innovators over their research trajectory (Nesta and Saviotti, 2005) as well as creating high barriers to entry in their technological niche (Winter, 1984; Malerba and Orsenigo, 1996; 1999). Therefore, we hypothesise:

Hypothesis 5. Compared to large serial innovators, small serial innovators benefit more from innovations defined by high technological impact to enhance their rate of innovation.

\section{Data}

We define as serial innovators those companies that are independent throughout the observation period, with at least five years of technological patenting activity calculated as the difference between the first and the last patent published by the company in the period of time considered and that possess at least 10 patented inventions with an overall ratio of patents to years at least equal to $1^{3}$. Small serial innovators are then defined as having less than 250 employees ${ }^{4}$.

The use of patent data is widespread in the literature as patents are officially recorded and easily accessible, provide a large quantity of detailed data at the firm level and are available 
for long time series. Moreover, the inventive step required to obtain a patent ensures an objective degree of novelty. Drawbacks are also well known ${ }^{5}$. In particular, patents are criticised for the wide variance in their value, yet several studies indicate that the use of patents weighted by citation, also utilised in the paper, may resolve this issue (Trajtenberg, 1990; Hall et al., 2005).

To build our dataset, we proceeded as follows. All applicants based in the UK with at least one patent application between the years 1990 and 2006 were selected. Then, single inventors or University applications were excluded. The data were manually checked to identify misspelled names or different names referring to the same entity. At this stage, a set of roughly 30 thousand companies was obtained. Patent families were used as a proxy for firms' inventions ${ }^{6}$, with patent family being defined as "a set of patents taken in various countries to protect a single invention" (OECD, 2001). This allowed us to uniquely identify single inventions, regardless of the number of applications made in different patent offices to protect the same new technology $y^{7}$

In order to complete the dataset with information on economic and business variables such as size, ownership and SIC code, all records were integrated with information from the FAME database and Companies House website, which contains the official UK register of companies. Then, all patents belonging to subsidiaries which were part of a group throughout the period of time considered were grouped together with the main holding company in order to enable consistent counting of patents.

Following our definition, at the end of this process a total of 1410 serial innovators were identified. However, for 296 companies it has not been possible to extract information on size, ownership and sector, and they have been removed from the analysis. Excluding also those companies which changed ownership and therefore, presented multiple links with 
various business groups in the period of time considered, the final dataset contained information on 811 companies: 472 large and 339 small companies.

\subsection{Serial innovators: some stylised facts}

Table 1 reports descriptive statistics for the firms in our dataset by size group. As expected, the differences between large and small-sized companies are sensible, with the first group accounting for the large majority of patents in the dataset, with the mean equal to 126 patents for large firms and 20 for small ones. Such difference is largely due to the higher skewness for large companies. In fact, as the second quartile underlines, half of the large companies have less than 37 patents, with the ten highest patenting companies holding almost one third of the patents considered. Instead, small companies show a median value of 16 inventions over the sixteen years analysed.

Considering the difference between the first application and the last in this time-period, the difference between large and small companies is less noticeable; with a mean of respectively 12 and 10 years. It is interesting to note that the majority of small serial innovators are not short-lived, with half of the small companies being active for at least 9 years in the period of time considered. If we look at the date of incorporation, many are much longer lived, with the average number of years of innovative activity being equal to 20 .

A detailed distribution across industrial sectors of small sized companies is reported in Table

2. Research \& Development is the most represented sector, accounting for roughly a third of the total number of companies (28\%). The manufacturing sectors constitute the other main group in the data, with the predominance of metal products and machinery (10\% and 6\%) followed by plastic products, precision instruments and chemical products $(6 \%, 6 \%$ and $4 \%$ respectively). 
[Tables $1 \& 2$ about here]

\section{Model specification}

We model the inventive performance of serial innovators as a function of two broad categories of explanatory variables reflecting the characteristics of technological regimes (see Hypotheses 1 to 3 ) and the quality of the technology specific inventive activity, (see Hypotheses 4 and 5) as discussed in Sections 2.1 and 2.2. Within the first category, we include opportunity conditions (OPPORTR), one variable for properties of the knowledge base (KNOWTR) and two distinct variables to reflect cumulativeness, namely, scale of previous innovation (SCALE) and search depth (SELFCITE). Within the second category, we measure technology specific characteristics including impact (IMPIN), generality (GENIN) and originality (ORIGIN) of innovation.

To investigate if any significant differences exist across small and large firms, we make use of firm size interaction terms. To test the robustness of our results we also estimate the model for small and large firms separately.

\subsection{Dependent Variables}

In order to measure the rate of innovation of serial innovators, we use the number of patents applied for by firm $i$ with publication date in year $t$ (PATENTS $\left.{ }_{i t}\right)$. However, patents present a significant variance in their individual technological and economic value. To account for this issue, a recent strand of literature has focused on the use of citation-based indices, providing evidence that patent citations are significantly correlated with the technological importance of inventions (Trajtenberg, 1990; Trajtenberg et al., 1997, Hall et al., 2001). Accordingly, we use a second dependent variable which is the citation-weighted patent count CITATIONS $_{\mathrm{it}}{ }^{8}$. 


\subsection{Independent Variables}

\subsubsection{Proxies for the Characteristics of Technological Regime}

The first group of independent variables refers to the concept of technological regime and describes the nature of the technological environment that bounds firms' knowledge base.

Given its complexity and the multifaceted nature, opportunity conditions (OPPORTR) have been formalized and measured in different ways in the applied literature. We follow the approach of Patel and Pavitt (1998) based on the increase in the patenting activity within a sector, and build an index of opportunity conditions (OPPORTR) by taking into account the year-over-year percentage increase in the number of patents for each IPC sector where the firm patented:

$$
\operatorname{OPPORTR}_{i t}=\frac{1}{P_{i t}} \sum_{p_{i t}=1}^{P_{i t}} \frac{a_{p, t}-a_{p, t-1}}{a_{p, t-1}}
$$

where $P_{i t}$ is the number of patents of the company $i$ in year $t$, while $a_{p, t}$ and $a_{p, t-1}$ represent the total number of patents in the same IPC technological class of the patent $p$ in time $t$ and $t$ 1 respectively.

Properties of the knowledge base (KNOWTR) refers to the nature of the technology and the knowledge embedded in the firm's innovative activities. Following Breschi et al. (2000), our measure is obtained by the relative number of patent citations made to science-based or applied sectors, with the number of patent citations on academic patents included in the first 
group, where positive values indicate a close relationship with science-based sectors. The index is:

$$
\operatorname{NNOWTR}_{i t}=\frac{c_{b, i t}+u_{i t}}{C_{i t}+u_{i t}}-\frac{c_{a, i t}}{C_{i t}+u_{i t}}
$$

where $c_{b}$ is the number of citations from science-based sectors and $c_{a}$ that of applied sectors. The $u$ represents citations made to university patents, while $C$ is simply $c_{b}+c_{a}$.

Cumulativeness summarizes the idea that inventions in time $t$ depend on existing knowledge capabilities and the previous level of innovation. To capture these aspects we use two distinct variables reflecting the cumulativeness effects in innovation: the scale of previous innovation (SCALE) and search depth (SELFCITE).

The first one is a proxy measure for dynamic economies of scale in innovation (see Bloom and Van Reenen, 2002; Hall et al., 2005) whereby increases in the volume of innovation up to a given time period lead to further increases in the innovation produced in subsequent periods. In line with the existing literature we measure the scale of previous innovation (SCALE) using the firm's patent stock:

$$
S C A L E_{i t}=P_{i t}+(1-\delta) S C A L E_{i t-1}
$$

where $P_{i t}$ represents the number of patents at the beginning of year $t$ and $\delta$ is the depreciation rate, which is assumed to be $15 \%^{9}$ (Cockburn and Griliches, 1988, Hall et al., 2005). Following Hall et al. (2005), we account for the effect of the missing initial condition by collecting information on the number of patents for all companies in the study from 1985, 
while our regressions use data starting from 1995, allowing for a lag of at least 10 years between the first year for which we have patent data and the first year analysed. To control for potential endogeneity, we allow SCALE to enter the estimating equation with a lag after being log transformed.

The second variable search depth (SELFCITE) may be considered a direct measure of the reuse of firms' previous knowledge and internal knowledge spillovers (Hall et al., 2005), and it is calculated as the average percentage of self-citations made by the ith firm in year $t$. In other words, this variable measures how intensively the firm dips into its own knowledge for generating further innovations. For every patent $p$, we count the number of citations made to other patents with the same assignee $\mathrm{Nsame}_{\mathrm{p}}$, divided by the total number of citations $\mathrm{N}_{\mathrm{p}}{ }^{10}$ :

SELFCITE $_{i t}=\frac{1}{P_{i t}} \sum_{p_{i t}=1}^{P_{i t}} \frac{\text { Nsame }_{p_{i t}}}{N_{p_{i t}}}$

\subsubsection{Proxies for Technology Specific Characteristics}

The second group of variables is used to test our fourth and fifth hypotheses on the characteristics of the technology developed internally to the firm. To control for potential endogeneity, these variables are lagged one period.

The impact of innovation (IMPIN) reflects the importance of patents in terms of both knowledge creation and as financial signals. In order to take into account the substantial differences in citation rates across different technologies and over time, we make use of the citation index proposed by Hicks and Hegde (2005), defined as the ratio of the citation count over the citation count of all patents in the same year and technological class. More formally we have: 
$\operatorname{IMPIN}_{i t}=\frac{1}{P_{i t}} \sum_{p_{i t}=1}^{P_{i t}} \frac{N_{f p_{i t}, k}}{N_{f t, k}}$

Where $N_{f p i t, k}$ represent the number of forward citations for the patent $p$ of company $i$ in the technology class $k$, while $N_{f t, k}$ is the total number of forward citations for any patent published in year $t$ in the same class $k$.

Generality of innovation (GENIN) is related to the idea that innovative companies benefit from the development of pervasive technologies which may generate successive innovations in different sectors. To calculate this variable, we follow the approach proposed by Trajtenberg et al. (1997). Including the bias correction presented in Hall (2005), the generality index is here defined for each patent as:

$$
\hat{G}_{p}=\operatorname{GENERALITY}_{p}=\frac{N_{f p}}{N_{f p}-1}\left(1-\sum_{k=1}^{K}\left(\frac{N_{f p, k}}{N_{f p}}\right)^{2}\right)
$$

where $\mathrm{K}$ is the number of different IPC technological classes where the patent was cited, $N_{f p, k}$ is the number of forward citations for the $k$ sector and $N_{f p}$ the total number of forward citations. The index is the inverse of the Herfindahl index, with values closer to 1 for patents with citations from a large spread across different technological classes and values close to 0 for patents cited in a small number of technological classes. Hence, the index for the generality of invention is defined for each company $i$ in year $t$ as follows: 
$\operatorname{GENIN}_{i t}=\frac{1}{P_{i t}} \sum_{p_{i t}=1}^{P_{i t}} \hat{G}_{p_{i t}}$

Originality of innovation (ORIGIN) is related to the argument that more original innovations build upon technological advances from a broad set of sectors. Following Trajtenberg et al. (1997), the index is calculated as the generality index, except that citations received are replaced by citations made by the company. Including the bias correction introduced above, we have:

$$
\hat{O}_{p}=\operatorname{ORIGINALITY~}_{p}=\frac{N_{b p}}{N_{b p}-1}\left(1-\sum_{k=1}^{K}\left(\frac{N_{b p, k}}{N_{b p}}\right)^{2}\right)
$$

where $K$ is the number of different IPC technological classes where the patent made citations, $N_{b p, k}$ is the number of backward citations made to the $k$ sector and $N_{b p}$ the total number of backward citations. Our originality index is:

$$
\operatorname{ORIGIN}_{i t}=\frac{1}{P_{i t}} \sum_{p_{i t}=1}^{P_{i t}} \hat{O}_{p_{i t}}
$$

\subsubsection{Firm Size and Other Control Variables}

To study the role of firm size, we run separate regressions on the samples of small and large serial innovators. To directly compare if significant differences exist in the size of the marginal impact and to test the robustness of our results, we also estimate the model over the full sample of serial innovators making use of a firm size dummy variable (SMALL) equal to one if the company has less than 250 employees. In order to test out the differences in how these variables affect small and large companies we allow SMALL to interact with 
OPPORTR, KNOWTR, SCALE, SELFCITE, IMPIN, GENIN and ORIGIN. We also include sectoral $^{11}$ and time dummies as control variables.

Table 3 reports the descriptive statistics for all variables used in the regressions. We observe that large serial innovators have a higher average value for patents, citations and knowledge stock but also much dispersion around the mean. Interestingly, small serial innovators present a more sustained level of self-citations, as well as generality and originality within their technological output. Finally, correlation figures from Table 4 as well as VIF and Tolerance values reported in Table 3 suggest that multicollinearity is not a significant concern in this study.

[Tables $3 \& 4$ about here]

\subsection{The negative binomial count model and truncation}

Given the stochastic nature of the inventive process, the flow of patenting activity of a company is usually dotted with years where a new discovery or invention does not take place. Hence, given the discrete and non-negative nature of both our dependent variables PATENTS and CITATIONS, traditional linear estimators such as ordinary least squares are limited, yielding inconsistent, inefficient and biased estimates (Cameron and Trivedi, 1998). In this case, count models provide a more appropriate means of analysis.

The common starting point for count data is the Poisson model. However, one of the main assumptions of the Poisson model is that the conditional mean should equal the conditional variance. To test the mean-variance assumption, we run Z-tests and the Lagrange Multiplier test for over-dispersion, with both tests rejecting the hypothesis of no over-dispersion at the

.01 level $^{12}$ (Hilbe, 2011). Many possible extensions have been proposed to account for this 
issue (See Hausman et al., 1984; Cameron and Trivedi, 1998). Among these, negative binomial models are the most common, and constitute the standard approach in the studies based on patent counts. To fit such model, we make use of generalized estimating equations (GEEs), first proposed by Liang and Zeger (1986), with a negative binomial distribution ${ }^{13}$. Another common problem when using citation data is that of truncation. To address this issue, we follow the fixed-effects approach discussed by Hall et al. (2001), which is built around the assumption that all systematic variations across different cohorts of patents are artefactual and therefore should be removed.

\section{Results}

In Table 5, we report the results of the negative binomial model. For both measures of innovativeness (PATENTS and CITATIONS), we separately report the results for small firms (column 1 and 2), large firms (column 3 and 4) and all serial innovators with interactions by firm size in the sample (column 5 and 6). As good practice when analysing interaction variables in nonlinear models and for ease of interpretation, the coefficients are expressed in terms of incidence rate ratios (IRRs) in all models. IRRs can be read as the percentage increase/decrease in the dependent variable following a unit change in the independent variable, ceteris paribus ${ }^{14}$. The percentage increase/decrease in the dependent variable is determined by whether the IRR coefficient is below or above 1. For example, an IRR of 1.270 on the OPPORTR variable in column (1) of Table 5 indicates that the patenting rates increase by $27 \%$ for every one unit of increase in the OPPORTR variable while the IRR of 0.857 on the KNOWTR variable suggests that patenting rates decrease by an average of $14.3 \%$ (1-0.857) for every 1 unit increase in KNOWTR. The interaction effects and their statistical significance can also be observed directly, although the effect should be read in multiplicative terms. In column (5) of Table 5, for example, the effect of OPPORTR for small 
firms is expected to decrease by $5.5 \%$ with respect to large companies, based on the estimated coefficient of the OPPORTR_SM variable.

[Table 5 about here]

In line with Hypothesis 1, we find the impact of the variables reflecting the characteristics of technological regimes (OPPORTR, KNOWTR, SCALE and SELFCITE) is significant for all serial innovators irrespective of the firm size (see column 1 to 6). The estimates are consistent across both dependent variables (PATENTS and CITATIONS) with the exception of the impact of SELFCITE upon PATENTS for large serial innovators. This issue is discussed in more detail below.

For small serial innovators, opportunity conditions present a positive relationship with the rate of innovation, with a one unit increase in its value resulting in an increase in the rate of PATENTS by a factor of 1.27 and a factor of 1.48 for CITATIONS (see column 2). For large serial innovators, a one unit increase in the value of the OPPORTR variable results in an increase in the rate of PATENTS by a factor of 1.33 and a factor of 1.44 for CITATIONS (see column 3 and 4 respectively). These results confirm that an economic environment replete with new technological discoveries (captured by the OPPORTR variable) provides fertile ground for the innovation activities of both the small and large serial innovators. With respect to KNOWTR, the IRRs less than 1 in columns (1) (2) and (3) (4) suggest that both small and large serial innovators benefit from having linkages with applied sectors, as opposed to basic sectors.

Our findings indicate that cumulativeness (SCALE and SELFCITE) exerts an overall positive effect on the rate of innovation for both small and large serial innovators. Yet, important 
differences also emerge. In particular, the impact of SCALE is lower for small serial innovators across both dependent variables (PATENTS and CITATIONS), suggesting that accumulated knowledge stock enhances the rate of innovations more for large serial innovators compared to their small counterparts as proposed in Hypothesis 2.

The impact of search depth (proxied by the SELFCITE variable) is also different for small and large serial innovators. We find that the variable SELFCITE exerts a negative effect upon PATENTS for large companies as shown in column (3) (i.e. IRR smaller than 1) and a relatively lower effect (IRR=1.314) upon CITATIONS compared with the case of small firms (IRR=1.917). These findings suggest that even though the process of search depth increases the quality of innovation across large firms, the increased search depth appears to restrict the quantity of further innovations large firms can introduce.

Overall, comparing small and large serial innovators, our findings indicate that processes of search depth building on firms' core competencies are particularly effective for generating further innovations across small serial innovators. These results support Hypothesis 3 .

To better capture the significance of any differences across firms of different size, we include a size dummy (SIZE) and size interaction variables in the models reported in column 5 and 6 to better understand how firm size moderates the effects of the sets of variables we focus on in the analysis. We note that the coefficient of the SMALL dummy variable is insignificant in both columns, revealing that there are no significant differences in the patenting rates of small and large serial innovators once we account for technological regime specific and technology specific variables. This is an interesting insight that highlights the similarities between the innovation rates of small and large serial innovators. 
Looking at the interaction variables, opportunity conditions have an effect that is around $6 \%$ higher for large companies (see column 5), suggesting that small serial innovators may be less responsive than large serial innovators to opportunities presented by the technological environment. This is in line with our earlier finding that their innovation activity may be characterized more by search depth based on the degree of specialisation within the technology class and the exploitation of internal capabilities and competencies, providing additional evidence for Hypothesis 3.

Small companies seem to be slightly more related to basic science technologies compared to large companies even though the coefficient of KNOWTR_SM is significant only at 10\% level in column (5) and not significant at all in column (6).

The estimates related to cumulativeness SCALE_SM and SELFCITE_SM reveal the most important differences between small and large firms. In line with Hypotheses 2, the positive effect on PATENTS derived from having a larger patent stock is reduced for small companies by around $15 \%$ compared to large companies. On the other hand, we observe the opposite effect for SELFCITE_SM, which is 1.3 times higher among small serial innovators for the model based on PATENTS and 1.5 times higher with respect to CITATIONS, providing further support for Hypothesis 3.

To test Hypothesis 4, we refer to the second group of variables classified under Technology Specific variables. Our results reveal that high impact innovations (IMPIN) increase the patenting rate for small serial innovators across both dependent variables (PATENTS and CITATIONS). The same cannot be said for large firms, where a significant and positive effect is found only for CITATIONS.

Looking at differences across firm size, we note that IMPIN exerts a positive increase in the rate of CITATIONS by a factor of 1.204 for small firms compared to a factor of 1.157 for 
large firms, offering evidence for Hypothesis 5. Further evidence for Hypothesis 5 is provided by the interaction variable (column 5 and 6) for high impact patents (captured by IMPIN_SM), which indicates a stronger positive effect on the rate of patenting activity (PATENTS) of small compared to large serial innovators. These results confirm that high quality innovations are particularly important for small serial innovators that have a smaller knowledge stock but act as important specialised technology providers in the market.

Considering the other Technology Specific variables, we find no evidence that either generality (GENIN) or originality (ORIGIN) of innovation have a significant impact upon the citation rate of serial innovators with respect to PATENTS. In the case of CITATIONS, we observe a positive effect for ORIGIN among small serial innovators (see column 2). This suggests original patents, as high impact innovations, may also reinforce the competitive advantage of small serial innovators within their technological trajectory.

Looking at the interactions, we observe higher generality (GENIN_SM) to have a stronger effect for large firms when considering CITATIONS. The unexpected negative effect for GENIN_SM may point to the importance of complementary capabilities available to large firms in order to fully exploit the 'enabling' effect of generic technologies. In the case of ORIGIN_SM, no significant difference is found with respect to either patents or citations of small serial innovators.

\section{Conclusions}

This paper shows that sustained innovative activity over time is not a specific quality of large companies but extends to a significant number of highly innovative small companies. We argue that, irrespective of the size of the firm, the nature of innovation persistence lies within 
the technological regimes defined by high opportunity conditions and cumulativeness, with technology specific characteristics of the innovation having contrasting effects. However, differences between small and large serial innovators reside in the very nature and characteristics of knowledge accumulation defined by the scale and depth of innovative search as well as in the technological impact of innovations. Empirically, we examine persistence in innovation using UK firm level patent data sourced from the PATSTAT database. In particular, we test the impact of the technological regimes and technology specific characteristics upon the rate of innovation of 811 UK serial innovators responsible for over 66000 patents during the period 1990-2006. Our findings provide evidence that opportunity conditions and cumulativeness are central elements in persistent innovation, with the specific qualities of cumulativeness representing the main difference between small and large serial innovators. While the higher resources and output of large firms allow them to benefit more from economies of scale in innovation, small companies have higher returns from processes of search depth defined by reuse of internal knowledge through 'combinative' capabilities to generate further innovations. Accordingly, we also find that small serial innovators benefit more from high-quality patents that reflect knowledge specialization in specific technological fields.

The study has certain limitations. First, although patents constitute an important means of appropriability for small R\&D companies (Arundel, 2001), they allow to study only a specific kind of serial innovators. Patents are more widespread in certain industries and technologies (Arundel and Kabla, 1998), thus our results must be considered cautiously outside those sectors where patents are usually applied for. In particular, we were not able to test the role of appropriability, and we deem this an interesting area for future research. Second, while this study has focused on the technological level of serial innovation, we believe that the role of finance and especially the presence of innovation networking are 
likely to be decisive elements in the activity of small serial innovators. We were unable to test these hypotheses and we deem it an interesting avenue for future research.

In summary, our results contribute to the literature on innovative persistence by highlighting the presence and importance of small serial innovators amongst the population of persistently innovating firms. We also shed light on the structural differences underlying innovative persistence for small and large serial innovators. The findings in this paper call for further research into better understanding the dynamics of knowledge generation and accumulation as well as innovation persistence within small serial innovators.

\section{References}

Acs, Z. J. and D. B. Audretsch (1987), 'Innovation, Market Structure, and Firm Size', The Review of Economics and Statistics, 69(4), 567-574.

Arundel, A. (2001), 'The relative effectiveness of patents and secrecy for appropriation', Research Policy, 30(4), 611-624.

Arundel, A. and I. Kabla (1998), 'What percentage of innovations are patented? empirical estimates for European firms', Research Policy, 27(2), 127-141. 
Audretsch, D. B. (1995), 'Innovation, growth and survival', International Journal of Industrial Organization, 13, 441-457.

Bloom, N., and J. Van Reenen (2002), 'Patents, Real Options and Firm Performance', Economic Journal, 112, C97-C116.

Breschi, S., Malerba, F. and L. Orsenigo (2000), 'Technological regimes and Schumpeterian patterns of innovation', The Economic Journal, 110(4), 388-410.

Breschi, S., Lissoni, F. and F. Malerba (2003), 'Knowledge-relatedness in firm technological diversification', Research Policy, 32, pp. 69-87.

Bresnahan, T. F. and M. Trajtenberg (1995), 'General purpose technologies 'Engines of growth'?', Journal of Econometrics, 6(1), 83-108.

Cameron, A. C. and P. K. Trivedi (1998). Regression analysis of count data. Cambridge University Press.

Carlile, P. R. (2002), 'A pragmatic view of knowledge and boundaries: Boundary objects in new product development,' Organization Science, 13(4), 442-455.

Cefis, E. and L. Orsenigo (2001), 'The persistence of innovative activities, a cross-countries and cross-sectors comparative analysis', Research Policy, 30(7), 1139-1158.

Chen, Y.-S., K.-C., Chang (2010) 'The relationship between a firm's patent quality and its market value - the case of US pharmaceutical industry',Technological Forecasting and Social Change, 77 (1), 20-33.

Cockburn, I. and Z. Griliches (1988), 'Industry effects and appropriability measures in the stock markets valuation of R\&D and patents', American Economic Review, 78(2), 419-423.

Cohen, W. M. and Klepper, S. (1996), 'A reprise of size and R\&D', The Economic Journal, 106, 925-951. 
Cohen, W. M. and D. A. Levinthal (1989), 'Innovation and Learning: The Two Faces of R\&D', The Economic Journal, 99, 569-596.

Cohen, W. M. and D. A. Levinthal, (1990), 'Absorptive Capacity: A New Perspective on Learning and Innovation', Administrative Science Quarterly, 35(1), 128-152.

Corradini, C., Battisti, G. and P. Demirel, (2012), 'Determinants of Technological Diversification in Small Serial Innovators', Nottingham University Business School Research Paper, n.2012-10.

Dosi, G. (1982), 'Technological paradigms and technological trajectories: A suggested interpretation of the determinants and directions of technical change', Research Policy, 11(3), $147-162$

Fleming, L. (2001), 'Recombinant uncertainty in technological search', Management Science, 47, 117-132.

Fleming, L. and O. Sorenson (2004), 'Science as a map in technological search,' Strategic Management Journal, 25(8-9), 909-928.

Freel, M. S. (2000), 'Strategy and structure in innovative manufacturing SMEs: the Case of an English Region', Small Business Economics, 15(1), 27-45.

Geroski, P. A., Van Reenen, J. and C. F. Walters (1997), 'How Persistently Do Firms Innovate?', Research Policy, 26(1), 33-48.

Granstrand, O., Patel, P. and K. Pavitt, (1997), 'Multitechnology corporations: Why they have "distributed" rather than "distinctive core" competencies', California Management Review, 3(4), 8-25.

Griliches, Z. (1990), 'Patent Statistics as Economic Indicators: A Survey', Journal of Economic Literature, 28(4), 1661-1707. 
Hall, B. H. (2005), 'A Note on the Bias in Herfindahl-Type Measures Based on Count Data', Revue d'Économie Industrielle, Programme National Persée, 110(1), 149-156.

Hall, B. H., Jaffe, A. and M. Trajtenber (2001), 'The NBER Patent Citation Data File: Lessons, Insights and Methodological Tools', NBER Working Paper 8498.

Hall, B. H., Jaffe, A. and M. Trajtenber (2005), 'Market Value and Patent Citations', The RAND Journal of Economics, 36(1), 16-38.

Hausman, J., Hall, B. H. and Z. Griliches (1984), 'Econometric Models for Count Data with an application to the Patents-R\&D Relationship', Econometrica, 52(4), 909-938.

Hicks, D. and D. Hegde (2005), 'Highly innovative small firms in the markets for technology', Research Policy, 34(5), 703-716.

Hilbe, J. M. (2011). Negative binomial regression. Second edition. Cambridge University Press.

Katila, R. and G. Ahuja (2002), 'Something old, something new: a longitudinal study of search behavior and new product introduction', Academy of Management Journal, 45(6), 1183-1194.

Kim, D. J. and B. Kogut (1996), ‘Technological platforms and diversification', Organization Science, 7, 283-301.

Kogut, B and U. Zander (1992), 'Knowledge of the Firm, Combinative Capabilities, and the Replication of Technology', Organization Science, 3(3), 393-397.

Levin, R. C., Klevorick, A. K., Nelson, R. R. and S. G. Winter (1987), 'Appropriating the Returns from Industrial Research and Development', Brookings Papers on Economic Activity, 18(3), 783-832.

Levin, R C. and P. C. Reiss (1988), 'Cost-reducing and demand-creating R\& D with spillovers', Rand Journal of Economics, 19, 538-56. 
Liang, K. and S. Zeger (1986), 'Longitudinal Data Analysis Using Generalized Linear Models', Biometrika, 73(1), 13-22.

Malerba, F. and L. Orsenigo (1993), 'Technological regimes and firm behaviour', Industrial and Corporate Change, 2(1), 45-71.

Malerba, F. and L. Orsenigo (1996), 'Schumpeterian patterns of innovation are technologyspecific', Research Policy, 25(3), 451-478.

Malerba, F. and L. Orsenigo (1999), 'Technological Entry, Exit and Survival: An Empirical Analysis of Patent Data', Research Policy, 28, 643-660.

Malerba, F., Orsenigo, L. and P. Peretto (1997), 'Persistence of innovative activities, sectoral patterns of innovation and international technological specialization', International Journal of Industrial Organization, 15(6), 801-826.

Martinez, C. (2011), 'Patent families: When do different definitions really matter?', Scientometrics, 86(1), 39-63.

Nelson, R. R. and S. Winter (1982). An Evolutionary Theory of Economic Change. Belknap Press.

Nesta, L. and P. P. Saviotti (2005), 'Coherence of the knowledge base and the firm's innovative performance: evidence from the US pharmaceutical industry', The Journal of Industrial Economics, 53, 123-142.

OECD (2001), Science, technology and industry scoreboard: towards a knowledge-based economy. OECD Publishing.

Patel, P., and K. Pavitt (1998), 'The Wide (and Increasing) Spread of Technological Competencies in the World's Largest Firms: A Challenge to Conventional Wisdom', in A. D. Chandler, P. Hageström and Ö. Slölvell (Eds), The Dynamic Firm. The Role of Technology, Strategy, Organization, and Regions. Oxford: Oxford University Press. 
Schumpeter, J. A. (1942/2008). Capitalism, socialism and democracy. New York: Harper Perennial.

Sutton, J. (1991). Sunk costs and market structure. MIT Press.

Trajtenberg, M. (1990), 'A Penny for Your Quotes: Patent Citations and the Value of Innovations', The Rand Journal of Economics, 21, 172-187.

Trajtenberg, M., Henderson, R. and A. Jaffe (1997), 'University versus Corporate Patents: A Window on the Basicness of Invention', Economics of Innovation and New Technology, 5, $19-50$.

Winter, S. (1984), 'Technological competition in alternative technological regimes', Journal of Economic Behaviour and Organization, 5, 287-320.

Winter, S. (1987), 'Knowledge and competence as strategic assets', in D. J. Teece (Ed), The competitive challenge: Strategies for industrial innovation and renewal (pp. 159-184). Cambridge: Ballinger Publishing Company. 
TABLES

Table 1: Serial innovators: total number of patents (PAT), years of innovative activity (Year Diff.), average number of patents per year of innovative activity (Ratio)

\begin{tabular}{|l|l|lllllllll|}
\hline & & MEAN & SD & Q25 & Q50 & Q75 & MAX & MIN & Patents & Firms \\
\hline LARGE & PAT & 125.87 & 335.75 & 20 & 37.5 & 90 & 4832 & 10 & 59410 & 472 \\
& Year Diff. & 11.57 & 3.64 & 8 & 12 & 15 & 16 & 5 & & \\
& Ratio & 10.03 & 23.11 & 2.15 & 3.64 & 7.41 & 304.69 & 1 & & \\
\hline SMALL & PAT & 20.5 & 17.16 & 12 & 16 & 21 & 181 & 10 & 6948 & 339 \\
& Year Diff. & 9.59 & 3.44 & 7 & 9 & 12 & 16 & 5 & & \\
& Ratio & 2.3 & 1.72 & 1.38 & 1.83 & 2.5 & 17.22 & 1 & & \\
\hline TOTAL & PAT & 81.82 & 261.49 & 15 & 23 & 49 & 4832 & 10 & 66358 & 811 \\
& Year Diff. & 10.74 & 3.69 & 8 & 10 & 14 & 16 & 5 & & \\
& Ratio & 6.8 & 18.07 & 1.63 & 2.5 & 4.7 & 304.69 & 1 & & \\
\hline
\end{tabular}

Table 2: Small Serial innovators by industrial classification (Two-digit SIC code)

\begin{tabular}{|c|c|c|c|c|}
\hline Sector & SIC Code & Patents & $\%$ Firms & $\%$ Patents \\
\hline Extraction of Crude Petroleum and Natural Gas & 11 & 55 & $0.88 \%$ & $0.79 \%$ \\
\hline Manufacture of Wearing Apparel & 18 & 11 & $0.29 \%$ & $0.16 \%$ \\
\hline Manufacture of Pulp, Paperand Paper Products & 21 & 64 & $1.18 \%$ & $0.92 \%$ \\
\hline Manufacture of Chemicals and Chemical Products & 24 & 265 & $4.42 \%$ & $3.81 \%$ \\
\hline Manufacture of Rubber and Plastic Products & 25 & 367 & $6.19 \%$ & $5.28 \%$ \\
\hline Manufacture of Other Non-metallic Mineral Products & 26 & 37 & $0.59 \%$ & $0.53 \%$ \\
\hline Manufacture of Basic Metals & 27 & 20 & $0.59 \%$ & $0.29 \%$ \\
\hline Manufacture of Fabricated Metal Products, Except Machinery & 28 & 696 & $10.32 \%$ & $10.02 \%$ \\
\hline Manufacture of Machinery and Equipment Not Elsewhere Classified & 29 & 326 & $6.19 \%$ & $4.69 \%$ \\
\hline Manufacture of Office Machinery and Computers & 30 & 39 & $0.88 \%$ & $0.56 \%$ \\
\hline Manufacture of Electrical Machinery and Other Apparatus & 31 & 165 & $2.65 \%$ & $2.37 \%$ \\
\hline Manufacture of Radio, Television and Communication Equipment & 32 & 118 & $2.36 \%$ & $1.70 \%$ \\
\hline Manufacture of Medical, Precision and Optical Instruments & 33 & 413 & $5.90 \%$ & $5.94 \%$ \\
\hline Manufacture of Other Transport Equipment & 35 & 28 & $0.59 \%$ & $0.40 \%$ \\
\hline Manufacture of Furniture; Manufacturing Not Elsewhere Classified & 36 & 463 & $7.67 \%$ & $6.66 \%$ \\
\hline Wholesale Trade and Commission Trade & 51 & 133 & $2.36 \%$ & $1.91 \%$ \\
\hline Retail Trade, Except of Motor Vehicles and Motorcycles & 52 & 10 & $0.29 \%$ & $0.14 \%$ \\
\hline Post and Telecommunications & 64 & 95 & $1.47 \%$ & $1.37 \%$ \\
\hline Computer and Related Activities & 72 & 108 & $2.06 \%$ & $1.55 \%$ \\
\hline $\mathrm{R} \& \mathrm{D}$ & 73 & 2576 & $28.32 \%$ & $37.08 \%$ \\
\hline Other Business Activities & 74 & 652 & $9.73 \%$ & $9.38 \%$ \\
\hline Health and Social Work & 85 & 29 & $0.59 \%$ & $0.42 \%$ \\
\hline Recreational, Cultural and Sporting Activities & 92 & 68 & $0.88 \%$ & $0.98 \%$ \\
\hline Other Service Activities & 93 & 98 & $1.47 \%$ & $1.41 \%$ \\
\hline Miscellaneous & & 112 & $2.06 \%$ & $1.61 \%$ \\
\hline TOTAL & & 6948 & $100 \%$ & $100 \%$ \\
\hline
\end{tabular}


Table 3: Descriptive statistics

\begin{tabular}{|c|c|c|c|c|c|c|c|}
\hline \multicolumn{8}{|c|}{ Small Serial Innovators } \\
\hline & Mean & St.Dev & Median & Max & Min & VIF & Tolerance \\
\hline Patents & 3.30 & 3.19 & 2 & 44 & 1 & & \\
\hline Citations & 9.35 & 14.25 & 5 & 288 & 2 & & \\
\hline Opportr & 2.65 & 1.64 & 2.45 & 7.62 & -0.82 & 1.09 & 0.92 \\
\hline Knowtr & -0.21 & 0.80 & -0.50 & 1 & -1 & 1.05 & 0.95 \\
\hline Scale & 9.94 & 10.71 & 7.28 & 104.47 & 1 & 1.08 & 0.92 \\
\hline Selfcite & 0.35 & 0.59 & 0 & 4 & 0 & 1.13 & 0.89 \\
\hline Impin & 1.13 & 1.74 & 0.56 & 16.96 & 0 & 1.02 & 0.98 \\
\hline Genin & 0.39 & 0.33 & 0.40 & 1 & 0 & 1.17 & 0.86 \\
\hline Origin & 0.37 & 0.30 & 0.38 & 1 & 0 & 1.17 & 0.86 \\
\hline \multicolumn{8}{|c|}{ Large Serial Innovators } \\
\hline & Mean & St.Dev & Median & Max & Min & VIF & Tolerance \\
\hline Patents & 14.11 & 30.03 & 5 & 356.00 & 1 & & \\
\hline Citations & 32.93 & 85.45 & 9 & 1171.00 & 2 & & \\
\hline Opportr & 2.53 & 1.46 & 2.41 & 7.62 & -0.85 & 1.06 & 0.94 \\
\hline Knowtr & -0.36 & 0.69 & -0.67 & 1 & -1 & 1.06 & 0.95 \\
\hline Scale & 71.34 & 158.86 & 21.66 & 1749.12 & 1 & 1.07 & 0.93 \\
\hline Selfcite & 0.26 & 0.50 & 0 & 9 & 0 & 1.04 & 0.96 \\
\hline Impin & 1.26 & 1.49 & 0.97 & 21.15 & 0 & 1.02 & 0.98 \\
\hline Genin & 0.36 & 0.26 & 0.34 & 1 & 0 & 1.15 & 0.87 \\
\hline Origin & 0.34 & 0.22 & 0.34 & 1 & 0 & 1.16 & 0.86 \\
\hline
\end{tabular}

Table 4: Correlation matrix

\begin{tabular}{|c|c|c|c|c|c|c|c|c|c|}
\hline & Patents & Citations & Opportr & Knowtr & Scale & Selfcite & Impin & Genin & Origin \\
\hline Patents & 1.00 & & & & & & & & \\
\hline Citations & 0.87 & 1.00 & & & & & & & \\
\hline Opportr & 0.22 & 0.21 & 1.00 & & & & & & \\
\hline Knowtr & 0.04 & 0.05 & -0.05 & 1.00 & & & & & \\
\hline Scale & 0.87 & 0.76 & 0.16 & 0.06 & 1.00 & & & & \\
\hline Selfcite & 0.12 & 0.15 & 0.21 & -0.07 & 0.11 & 1.00 & & & \\
\hline Impin & 0.11 & 0.15 & 0.15 & -0.05 & 0.09 & 0.15 & 1.00 & & \\
\hline Genin & -0.01 & 0.01 & 0.00 & 0.11 & 0.00 & 0.04 & 0.05 & 1.00 & \\
\hline Origin & 0.01 & 0.02 & 0.00 & 0.10 & 0.01 & 0.05 & 0.09 & 0.36 & 1.00 \\
\hline
\end{tabular}


Table 5: GEE Negative binomial regression estimates for serial innovators

\begin{tabular}{|c|c|c|c|c|c|c|}
\hline & $\begin{array}{l}\text { (1) } \\
\text { PATENTS }\end{array}$ & $\begin{array}{l}(2) \\
\text { CITATIONS }\end{array}$ & $\begin{array}{l}\text { (3) } \\
\text { PATENTS }\end{array}$ & $\begin{array}{l}(4) \\
\text { CITATIONS }\end{array}$ & $\begin{array}{l}\text { (5) } \\
\text { PATENTS }\end{array}$ & $\begin{array}{l}(6) \\
\text { CITATIONS }\end{array}$ \\
\hline Sample Definition & Small Firms & Only & \multicolumn{2}{|c|}{ Large Firms Only } & \multicolumn{2}{|c|}{ Small and Large Firms } \\
\hline \multicolumn{7}{|c|}{ Technological regimes variables } \\
\hline Opportr & $\begin{array}{l}1.270 * * * \\
(0.022)\end{array}$ & $\begin{array}{l}1.483 * * * \\
(0.064)\end{array}$ & $\begin{array}{l}1.330 * * * \\
(0.019)\end{array}$ & $\begin{array}{l}1.443 * * * \\
(0.039)\end{array}$ & $\begin{array}{l}1.346^{* * *} \\
(0.018)\end{array}$ & $\begin{array}{l}1.477 * * * \\
(0.041)\end{array}$ \\
\hline Knowtr & $\begin{array}{l}0.857 * * * \\
(0.038)\end{array}$ & $\begin{array}{l}0.668^{* * *} \\
(0.075)\end{array}$ & $\begin{array}{l}0.846 * * * \\
(0.030)\end{array}$ & $\begin{array}{l}0.797 * * * \\
(0.052)\end{array}$ & $\begin{array}{l}0.827 * * * \\
(0.028)\end{array}$ & $\begin{array}{l}0.738 * * * \\
(0.053)\end{array}$ \\
\hline Scale & $\begin{array}{l}1.783 * * * \\
(0.070)\end{array}$ & $\begin{array}{l}1.848 * * * \\
(0.176)\end{array}$ & $\begin{array}{l}2.022 * * * \\
(0.032)\end{array}$ & $\begin{array}{l}1.963 * * * \\
(0.058)\end{array}$ & $\begin{array}{l}2.020 * * * \\
(0.031)\end{array}$ & $\begin{array}{l}1.957 * * * \\
(0.064)\end{array}$ \\
\hline Selfcite & $\begin{array}{l}1.190 * * * \\
(0.059)\end{array}$ & $\begin{array}{l}1.917 * * * \\
(0.263)\end{array}$ & $\begin{array}{l}0.910 * * \\
(0.039)\end{array}$ & $\begin{array}{l}1.314 * * * \\
(0.104)\end{array}$ & $\begin{array}{l}0.900 * * \\
(0.041)\end{array}$ & $\begin{array}{l}1.217^{* *} \\
(0.115)\end{array}$ \\
\hline \multicolumn{7}{|c|}{ Technology specific variables } \\
\hline Impin & $\begin{array}{l}1.059 * * * \\
(0.015)\end{array}$ & $\begin{array}{l}1.204 * * * \\
(0.044)\end{array}$ & $\begin{array}{l}1.012 \\
(0.014)\end{array}$ & $\begin{array}{l}1.157 * * * \\
(0.028)\end{array}$ & $\begin{array}{l}1.012 \\
(0.014)\end{array}$ & $\begin{array}{l}1.140 * * * \\
(0.031)\end{array}$ \\
\hline Genin & $\begin{array}{l}1.056 \\
(0.096)\end{array}$ & $\begin{array}{l}0.761 \\
(0.164)\end{array}$ & $\begin{array}{l}0.980 \\
(0.074)\end{array}$ & $\begin{array}{l}1.134 \\
(0.155)\end{array}$ & $\begin{array}{l}0.969 \\
(0.071)\end{array}$ & $\begin{array}{l}1.200 \\
(0.181)\end{array}$ \\
\hline Origin & $\begin{array}{l}1.051 \\
(0.115)\end{array}$ & $\begin{array}{l}1.571 * \\
(0.412)\end{array}$ & $\begin{array}{l}1.094 \\
(0.106)\end{array}$ & $\begin{array}{l}1.267 \\
(0.221)\end{array}$ & $\begin{array}{l}1.104 \\
(0.104)\end{array}$ & $\begin{array}{l}1.267 \\
(0.242)\end{array}$ \\
\hline \multicolumn{7}{|c|}{ Size and interaction variables } \\
\hline SMALL & & & & & $\begin{array}{l}1.042 \\
(0.138)\end{array}$ & $\begin{array}{l}0.743 \\
(0.174)\end{array}$ \\
\hline Opportr_SM & & & & & $\begin{array}{l}0.945 * * * \\
(0.0173)\end{array}$ & $\begin{array}{l}0.979 \\
(0.0365)\end{array}$ \\
\hline Knowtr_SM & & & & & $\begin{array}{l}1.102 * \\
(0.0546)\end{array}$ & $\begin{array}{l}1.017 \\
(0.102)\end{array}$ \\
\hline Scale_SM & & & & & $\begin{array}{l}0.863 * * * \\
(0.0374)\end{array}$ & $\begin{array}{l}0.947 \\
(0.0752)\end{array}$ \\
\hline Selfcite_SM & & & & & $\begin{array}{l}1.290 * * * \\
(0.0857)\end{array}$ & $\begin{array}{l}1.557 * * * \\
(0.213)\end{array}$ \\
\hline Impin_SM & & & & & $\begin{array}{l}1.046 * * \\
(0.0214)\end{array}$ & $\begin{array}{l}1.061 \\
(0.0419)\end{array}$ \\
\hline Genin_SM & & & & & $\begin{array}{l}1.066 \\
(0.131)\end{array}$ & $\begin{array}{l}0.634 * * \\
(0.147)\end{array}$ \\
\hline Origin_SM & & & & & $\begin{array}{l}0.967 \\
(0.148)\end{array}$ & $\begin{array}{l}1.317 \\
(0.379)\end{array}$ \\
\hline $\mathrm{N}$ Obs & 1152 & 1152 & 2359 & 2359 & 3511 & 3511 \\
\hline \multicolumn{5}{|c|}{ Lagrange Multiplier Test (p-value) } & & 0.001 \\
\hline
\end{tabular}

All columns report IRRs.

All regressions include year and sectoral dummies. S.E. in parentheses

$* \mathrm{p}<0.10 * * \mathrm{p}<0.05 * * * \mathrm{p}<0.01$ 
${ }^{1}$ We use this term, as opposed to persistent innovators, as our definition resembles the one introduced by Hicks and Hegde (2005).

${ }^{2}$ Potential differences may also occur for original and generic patents. However, while their presence may offer small companies additional opportunities to increase internal combinative capabilities and strengthen their position over a specialised technological trajectory, they often require complementary resources that are more likely to reside in large firms. Thus, we leave to the empirics to determine possible differences for originality and generality across firm size.

${ }^{3}$ The traditional approach to the study of persistent innovation focuses on the presence of innovation in subsequent periods of time. In this paper we follow the approach of Hicks and Hegde (2005), imposing a minimum threshold of innovative activity within a larger window of time. That allows us to focus on the overall stream of inventions rather than their sequence over time.

${ }^{4}$ This definition follows the European Commission Recommendation (96/280/EC) of 3 April 1996, where SMEs are defined by the upper of 250 employees. According to this threshold, only three small companies turned into large companies in the period considered. We have carried out a number of modelling exercises and we can conclude that their inclusion/exclusion does not significantly affect the parameters estimates. For obvious reasons no further analysis of their innovation mode and innovation performance was carried out.

${ }^{5}$ For a discussion of strengths and weaknesses of patent data see Griliches (1990).

${ }^{6}$ See Martinez (2011) for a detailed discussion on the use of patent families as proxies for firms' inventive activity.

${ }^{7}$ Note that, unlike studies that use patent data from a single patent office (e.g: USPTO), identification of patent families is crucial to this study in order to avoid multiple counting based on different patents issued for the same invention in different countries since PATSTAT combines patent applications from various patent offices.

${ }^{8}$ The weighting scheme adopted to obtain CITATIONS follows the approach presented by Trajtenberg (1990), who suggested to weight each patent $i$ by the total number of citations received in the following years. See also Section 5.3 for our approach to the issue of truncation in citations.

${ }^{9}$ As a further test we have also set $\delta=20 \%$ and $\delta=25 \%$, but estimates do not change significantly.

${ }^{10}$ Note that this is the index proposed by Trajtenberg et al. (1997) to measure appropriability.

${ }^{11}$ Sectoral dummies are based on the main technological class of firms' patent portfolio, as these reflect more accurately the nature of the knowledge base of companies than SIC codes. Also, their distribution is more balanced across large and small firms.

${ }^{12}$ We report the $\mathrm{p}$ value for the LM test in Table 5.

${ }^{13}$ We estimated the negative binomial heterogeneity parameter $\alpha$ using the STATA command nbreg, following Hilbe (2011).

${ }^{14}$ Incidence rate ratios are simply the ratio of two ratios, which are defined by the occurrence of an event in a given time period. 